\title{
Empirical Study on Dynamic Relationship between Industrial Structure and Employment Structure in Hunan*
}

\author{
Liu Xianghui, Jiang Sha \\ Oriental Institute of Science and Technology, Hunan Agricultural University, Changsha, People's Republic of \\ China
}

\begin{abstract}
The balanced relationship between the industrial structure and the employment structure is a crucial factor for the development of the regional economy. This study was conducted based on a descriptive analysis of the industrial structure and employment structure trends in Hunan Province. Through the methods of Co-integration Test and Granger Causality Test, Pulse Response Analysis and Variance Decomposition Analysis, this research examines the dynamic relationship between industrial structure and employment structure and proposes relevant suggestions.
\end{abstract}

KEYWORD: Industrial structure; Employment structure; Dynamic relationship

\section{INTRODUCTION}

Employment is of vital importance to people's livelihoods, and the optimization of industrial structure is the key to accelerate the transformation of the economic development mode. Industrial structure and employment structure are significant indicators to reflect the development of the social economy and the dynamic relationship between these is an important factor which affects the social economy at the regional level. [1-2]Existing studies demonstrate that adjustment of the industrial structure has a strong influence on the transformation of the employment structure and the rationalization of the employment structure will promote the optimization of the industrial structure. [3-5]It is essential for the industrial structure and the employment structure to maintain a dynamic and coordinated development. At present, facing the arduous tasks of upgrading and transforming the economy and developing social livelihood, Hunan is comprehensively promoting the construction of " $\mathrm{Si}$ Hua Liang Xing", and striving for "San Liang Qi Sheng", and thus progression into the new development stage "Liang Ge Jia Kuai, Liang Ge Shuai Xian. The careful analysis of the dynamic relation between Hunan's industrial structure and employment structure, especially the deep analysis of the internal connection between the production value of three industries and three industries' employment, is vitally important for the optimization of the industrial structure and the employment structure in Hunan, and the formulation of scientific, sensible, and effective industrial policies and employment policies, and thus boost the development to a higher level.

\section{THE EMPIRICAL ANALYSIS OF DYNAMIC RELATIONSHIP BETWEEN INDUSTRIAL STRUCTURE AND EMPLOYMENT STRUCTURE IN HUNAN}

Since the implementation of the reform and opening up policy, Hunan has experienced a steady and rapid economic development, with a constant increase in the value added of three major industries and continuous upgrading of the industrial structure. In terms of the structure of industries, the pattern of Hunan is "two-three-one". Hunan is in the middle stage of industrialization. With Hunan's economic and social development, the adjustment and optimization of industrial structure, and the growing ability to absorb labor forces, the number of employed people went up constantly. However, generally, a huge amount of labor force is still concentrated in the agricultural sector, which means the oversize of the first industry, insufficient labor force in second industry and tertiary industry. Therefore, it can be seen that, compared with the progress of the industrial structure, the employment structure is seriously lagging behind.

\footnotetext{
* Foundation Item: Project of the Twelfth Five-Year Plan in Educational Science of Hunan Province (Item Number: XJK012CGD055).
} 


\subsection{Co-Integration Test}

The Vector Autoregression Model (VAR) is a unstructured model, which is based on economic time series. It can construct functions by using all relevant independent variables in linear function as the lagged terms of independent variables in a system. Before the application of VAR, the ADF stationary test of the three major industries and the employment figures of each industry in Hunan should be conducted and thus it can be determined which test should be adopted: Johansen Cointegration Test or the Granger Causality test. In the ADF test, YG1, YG2, YG3, YG represent addedvalue and the GDP of the first, second, and tertiary industries respectively, and YE1, YE2, YE3 represent the employment figures of the three major industries in Hunan employment and total employment is indicated by YE4. The ADF test revealed that $\mathrm{YG}, \mathrm{YG} 2$ and $\mathrm{YG} 3$ are unstable original time series. And there is not any cointergration relationship among these three figures and hence the Granger Causality Test has been adopted. There exists I(2) in YG1 under the level of
$5 \%$ and $10 \%$. There is $\mathrm{I}(2)$ in YE4. Besides, I(1) exists among YE1, YE2 and YE3. I(2) exists between YG1 and YE4. These facts indicate that the original time series of the industrial structure of the three industries, the product of the first industry, and the total employment figure of Hunan became stable in a certain linear combination. Thus the Cointegration Test could be employed and then Vector Error Correct (VEC) model needs to be adopted.

The Unit Root Test above demonstrated the existence of a non-stationary but I(1) economic time series in the three major industries in Hunan, and thus the Co-Integration test was adopted. The Cointegration Test uses the VAR as its economic model $\left(Y_{t}=\alpha_{1} Y_{t-1}+\alpha_{2} Y_{t-2}+\cdots+\alpha_{m} Y_{t-m}+\beta_{1} X_{1}+\beta_{2} X_{2}+\cdots+\beta_{t} X_{t}+u_{t}\right)$.

Before the application of VAR model, the lagging order numbers for Endogenous were determined according to AIC and SC. After repeating tests, the lagging phase of the employment figure in the three major industries was identified as one, the lag phase of the total employment figure was identified as two. The Co-integration Tests results are shown in Table 1 and Table 2.

Table 1: Co-Integration Test of Employment Figure in the Three Major Industries in Hunan

\begin{tabular}{|c|c|c|c|c|c|c|}
\hline \multirow{2}{*}{$\begin{array}{l}\text { Figure of Co- } \\
\text { Integration }\end{array}$} & \multicolumn{2}{|c|}{ Trace Test } & \multirow[b]{2}{*}{ Probability } & \multicolumn{2}{|c|}{ Max-Eigenvalue Test } & \multirow[b]{2}{*}{ Probability } \\
\hline & Trace Statistics & $5 \%$ Critical Value & & Statistics of the Maximums & $\begin{array}{l}5 \% \text { Critical } \\
\text { Value }\end{array}$ & \\
\hline 0 & 37.85240 & 29.79707 & 0.0048 & 26.62550 & 21.13162 & 0.0076 \\
\hline 1 & 11.22690 & 15.49471 & 0.1979 & 10.72881 & 14.26460 & 0.1683 \\
\hline 2 & 0.498087 & 3.841466 & 0.4803 & 0.498087 & 3.841466 & 0.4803 \\
\hline
\end{tabular}

Table 2: Co-Integration Test of the Production Value of First Industry and Total Employment Figure in Hunan

\begin{tabular}{|c|c|c|c|c|c|c|}
\hline \multirow{2}{*}{$\begin{array}{l}\text { Figure of Co- } \\
\text { Integration }\end{array}$} & \multicolumn{2}{|c|}{ Trace Test } & \multirow[b]{2}{*}{ Probability } & \multicolumn{2}{|c|}{ Max-Eigenvalue test } & \multirow[b]{2}{*}{ Probability } \\
\hline & Trace Statistics & $5 \%$ Critical Value & & Statistics of the Maximums & $\begin{array}{c}5 \% \text { Critical } \\
\text { Value }\end{array}$ & \\
\hline 0 & 20.46377 & 15.49471 & 0.0082 & 19.27985 & 14.26460 & 0.0074 \\
\hline 1 & 1.183921 & 3.841466 & 0.2766 & 1.183921 & 3.841466 & 0.2766 \\
\hline
\end{tabular}

As can be seen from Figure 1, there was only one co-intergration in the three major industries in Hunan, which is the long-term equilibrium relationship among the three industries. And a longrun and stable development trend exists in the employment in the three major industries.

$$
\text { YE1=-4.037552YE2+ 0.736826YE3 }
$$

standard deviation $=(1.02838)(0.54416)$

As can be seen from Figure 2, there was only one cointergration between the production value of the first industry and the total employment figure in Hunan. The total employment figure is closely related to the first industry. That is:

\section{$\mathrm{YG} 1=0.017648 \mathrm{YE} 4$ \\ standard deviation $=(0.17813)$}

With the aim to analyze the variation corelation among the employment structure in the three major industries, the production value of the first industry and the total employment figure, this article will use the above linear function to correct the vector model. The estimated results of VEC model are as follows:

$$
\begin{aligned}
\Delta Y E_{t} & =\left[\begin{array}{c}
-26.89766 \\
3.865190 \\
55.15536
\end{array}\right]+\left[\begin{array}{ccc}
1.082546 & 0.470519 & 0.4716214 \\
-0.090018 & 0.383513 & 0.201916 \\
-0.675624 & -0.398210 & -.0335941
\end{array}\right] \Delta Y E_{t-1} \\
& +\left[\begin{array}{c}
-0.075070 \\
0.093303 \\
0.068265
\end{array}\right] V_{t-1}+\hat{\varepsilon}_{t}
\end{aligned}
$$

And,

$$
\begin{aligned}
Y E_{t} & =\left(Y E 1_{t}, Y E 2_{t}, Y E 3_{t}\right)^{\prime}, V E C M_{t-1} \\
& =1309.349+Y E 1_{t}+1.780939 Y E 2_{t}-0.768694 Y E 3 t
\end{aligned}
$$


$\mathrm{t}=-6.32267 \quad 5.47232$

\section{$\mathrm{R}^{2}=0.365895 \quad 0.524921 \quad 0.108291$}

The results show that if the employment figure in the second industry rises by $1 \%$, the employment figure in the first industry will decline by $1.780939 \%$ and if the employment figure in the tertiary industry rises by $1 \%$. The employment figure of the first industry will rise by $0.768694 \%$. This means the pace of the industrial development is fast and the ability to absorb surplus rural labor has been further improved. But there are still some problems: the internal structure of the tertiary industry is unreasonable, new services are not fully developed, the proportion of high traditional services are too high, the scale of producing service industry is relatively small but the proportion of daily service industry is relatively high, many laborers in the tertiary industry go farming during busy seasons and they will go to work during slack seasons, and the professionalism and specialization of the staff in the tertiary industry needs to be enhanced.

$$
\begin{aligned}
& \Delta Y N_{t}=\left[\begin{array}{c}
5.467059 \\
22.56149
\end{array}\right]+\left[\begin{array}{ll}
0.297276 & 1.041569 \\
0.049911 & 0.335508
\end{array}\right]{ }_{t-1}^{\Delta Y N} \\
& +\left[\begin{array}{cc}
-0.497873 & 0.650800 \\
0.022484 & 0.118112
\end{array}\right] \Delta_{t-2}^{\Delta Y N} \\
& +\left[\begin{array}{c}
0.195364 \\
-0.023358
\end{array}\right] V_{t-1}+\hat{\varepsilon}
\end{aligned}
$$

And,

$$
\begin{aligned}
Y N_{t} & =\left(Y G 1_{t}, Y E 4_{t}\right)^{\prime}, V E C M_{t-1} \\
& =761.7105+Y G 1_{t}-0.017648 Y E 4_{t} \\
\mathrm{t} & =0.09907 \\
\mathrm{R}^{2} & =0.699414 \quad 0.538014
\end{aligned}
$$

The results show that if the total employment rate increases by $1 \%$, the production value of the first industry will increase by $0.017648 \%$, indicating that Hunan is still a major agricultural province; the number of people who work in agricultural sector is the largest among the three major industries, the development of agriculture lags behind and the agricultural productivity is low.

\subsection{Causality Test}

It can be seen from the ADF stationary test that there is not any co-intergration relationship among the three major industrial structures. This study adopts the Granger Causality Test to identify the dynamic relationship between the industrial structure and the employment structure of the three major industries. The testing method is as follows: if the variable $\mathrm{Y}$ changes before the variable $\mathrm{X}$, then $\mathrm{Y}$ will change

\begin{tabular}{|c|c|c|c|c|}
\hline The Null Hypothesis & $\begin{array}{l}\text { Sample } \\
\text { Size }\end{array}$ & $\begin{array}{l}\text { Detection } \\
\text { Value of F }\end{array}$ & $\begin{array}{l}\text { Values } \\
\text { of P }\end{array}$ & $\begin{array}{c}\text { Judgement of } \\
\text { Original Judgment }\end{array}$ \\
\hline Total employment figure is not the Granger reason of GDP & \multirow{2}{*}{32} & 4.16448 & 0.0265 & Reject \\
\hline GDP is not the Granger reason for total employment figure & & 0.00110 & 0.9989 & Accept \\
\hline $\begin{array}{l}\text { The employment figure of the first industry is not the Granger reason for } \\
\text { the production value of the first industry }\end{array}$ & \multirow{2}{*}{32} & 0.47224 & 0.6287 & Accept \\
\hline $\begin{array}{l}\text { The production value of the first industry is not the Granger reason for the } \\
\text { employment figure in the first industry }\end{array}$ & & 2.46823 & 0.1036 & Accept \\
\hline $\begin{array}{l}\text { The employment figure of the second industry is not the Granger reason } \\
\text { for the production value of the second industry }\end{array}$ & \multirow{2}{*}{32} & 5.15689 & 0.0127 & Reject \\
\hline $\begin{array}{l}\text { The production value of the second industry is not the Granger reason for } \\
\text { the employment figure of the second industry }\end{array}$ & & 0.31392 & 0.7332 & Accept \\
\hline $\begin{array}{l}\text { The production value of the tertiary industry is not the Granger reason for } \\
\text { the employment figure in tertiary industry }\end{array}$ & \multirow{2}{*}{32} & 0.02793 & 0.9725 & Accept \\
\hline $\begin{array}{l}\text { The production value of the tertiary industry is not the Granger reason of } \\
\text { the employment figure of the tertiary industry }\end{array}$ & & 0.65399 & 0.5280 & Accept \\
\hline
\end{tabular}
before $X$, the following econometric model will be established:

$$
Y_{t}=\sum_{t=1}^{T} \alpha_{i} X_{t-i}+\sum_{t=1}^{T} \beta_{j} Y_{t-j}+u_{t}
$$

The results of Granger Causality Test of the above model is shown in Table 3:

Table 3: Granger Causality Test of the Industrial Structure and Employment Structure

The results of the Granger Causality Test results show that the total employment figure is the Granger reason for the GDP, but not vice versa. This indicates that, in Hunan Province, the changes in total employment figure will lead to the changes in total GDP. But because the tertiary industry in Hunan is underdeveloped and the ability to absorb the labor force is not strong, the increase in GDP under the influence of the second industry won't necessarily promote the growth in the total employment figure, but not vice versa. The employment figure of the second industry is the Granger reason for the production value of the second industry, but not vice versa. This phenomenon reveals that, with the development of the social economy, the constant expanding of the 
second industry led to the growth in the employment figure in the second industry, and the rapid increase in the production value of the second industry. Besides, during the process of accelerating industrialization, heavy chemical industry such as steel, nonferrous metals, engineering machinery and automobiles have enjoyed major support, and the trend of "heavy industrialization" is evident. However, the heavy chemical industry belongs to capital- and -technology-intensive industries and its ability to absorb labor force is quite weak. The rapid development of the heavy chemical industry will intensify the problem that capital excludes labor force. Thus, the rapid development of the second industry will not necessarily promote the simultaneous growth of the employment figure in the second industry.

\subsection{Impulse Response Analysis and Variance Decomposition Analysis}

The above analysis shows that even though there is not any co-intergration relationship between the GDP and total employment figure, there is Granger causality. Therefore, we could construct an impulse response function and a variance decomposition function to analyze the influence on the current value and future value of other endogenous variables caused by the endogenous variables random disturbance term standard deviation shocks. And the functions are as follows: $Y_{1 t}=\beta_{11} Y_{1 t-1}+\beta_{12} Y_{2 t-1}+u_{1 t}$, $Y_{2 t}=\beta_{21} Y_{1 t-1}+\beta_{22} Y_{2 t-1}+u_{2 t}$. In these functions, if the disturbance $u_{1}$ changes, the $Y_{1}$ will change, and in the mean time, the corresponding value of the $Y_{21}$ will also change. Due to the lagging impact, the changes of $Y_{2 t}$ will cause the changes of the future value of $Y_{1 t}$. The impulse response function, derived from the mutual standards of total GDP employment figure and GDP, is shown in Figure 1:
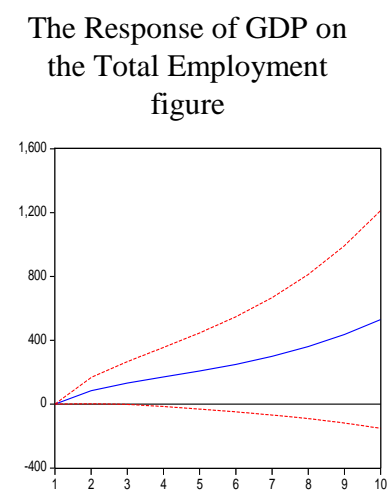

The Response of Total

Employment Figure on GDP

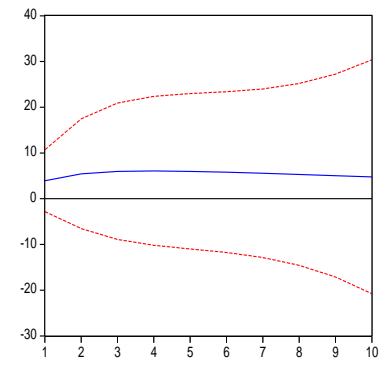

Figure1 The Repulse Response Function of GDP and Total Employment Figure

As above, the horizontal axis represents the number of the number of months lagged behind and the vertical axis represents the size of the impulse function. The red dashed line represents the standard deviation band and the solid blue line represents the degree of the impulse response. The left figure demonstrates that, after the positive impact of total employment figure, both the GDP and the total employment figure increased gradually. This indicates that, in the short term, the impact of total employment figure on the GDP is not obvious. However, in the long run, the impact is significant and long-lasting. The right figure reveals that the total employment figure responds to the impact of the GDP, and they fluctuate in the same direction. This kind of impact, in the early period, will increase moderately, but in the long run, it will become stable.

The impulse of above variables is the related changes of variables caused by a single variable and variance decomposition is the construction for endogenous variables contributed by the impact of every structures. The model of variance decomposition is as follows:

Table 4: Variance Decomposition of the GDP and Total Employment Figure

\begin{tabular}{|c|c|c|c|c|c|c|}
\hline \multirow{2}{*}{$\mathrm{T}$} & \multicolumn{3}{|c|}{ Variance Decomposition of GDP } & \multicolumn{2}{c|}{ Variance Decomposition of Total Employment Figure } \\
\cline { 2 - 7 } & S.E. & Total Employment Figure & GDP & S.E. & Total Employment Figure & GDP \\
\hline 1 & 230.4693 & 0.000000 & 100.0000 & 19.30121 & 95.84407 & 4.155934 \\
\hline 2 & 378.7848 & 5.010796 & 94.98920 & 33.55061 & 95.99529 & 4.004710 \\
\hline 3 & 540.3726 & 8.448912 & 91.55109 & 45.29164 & 96.05801 & 3.941995 \\
\hline 4 & 722.3594 & 10.27285 & 89.72715 & 54.93342 & 96.09536 & 3.904640 \\
\hline 5 & 932.9602 & 11.09962 & 88.90038 & 62.93645 & 96.12289 & 3.877109 \\
\hline 6 & 1181.801 & 11.36887 & 88.63113 & 69.67506 & 96.14653 & 3.853474 \\
\hline 7 & 1480.225 & 11.34068 & 88.65932 & 75.42790 & 96.16909 & 3.830913 \\
\hline 8 & 1841.757 & 11.16479 & 88.83521 & 80.39806 & 96.19218 & 3.807820 \\
\hline 9 & 2282.700 & 10.92673 & 89.07327 & 84.73414 & 96.21688 & 3.783121 \\
\hline 10 & 2822.882 & 10.67442 & 89.32558 & 88.54654 & 96.24402 & 3.755982 \\
\hline
\end{tabular}


As above, in term of the forecast variance of the GDP, $100 \%$ of the forecast variance is caused by the disturbance of the GDP itself in the first period, but in the third period, $91.6 \%$ of the forecast variance is induced by the GDP itself and $8.4 \%$ is contributed by total employment figure. Under the influence of the total employment figure, the GDP decreased from the first period, and began to increase since the seventh period, and it suffered little from its fluctuation. Meanwhile, the total employment figure increased from the first period and decreased from the seventh period, which means the total employment figure has a certain amount of influence on the GDP in the short term but it has little impact in the long run. In the forecast variance of the total employment figure, the total employment figure is influenced by the GDP, and it suffered a lot from its fluctuation, and it gradually increased, but the GDP gradually decreased. Therefore, GDP has influence on the total employment figure, and this influence is significant in the long term.

\section{CONCLUSIONS AND RECOMMENDATIONS}

Research on the dynamic relationship between the industrial structure and employment structure in Hunan Province show that there exists a unique cointegration relationship employment structure among the three major industries in Hunan Province, which means the relationship of the employment of the three major industries are long-term and stable; There is a co-intergration relationship between the production value of the first industry and the total employment figure under the level of $5 \%$ and $10 \%$, which means the development of the first industry lags behind and the agricultural productivity is low, and there is an excessive surplus of labor ; the total employment figure is the Granger reason of the GDP, but not vice versa, which means the promotion effect of rapid development of Hunan's economy on employment is not significant, and the phenomenon that "high economic increase and low employment" emerged, especially the phenomenon that the ability of the tertiary industry to absorb the labor force is not strong; the employment figure of the second industry is the Granger reason for the production value of the second industry, but not vice versa, which means the development between the capitaland-technological-intensive industries and the laborintensive industry is not balanced, and the advantages of human resource have not been given a full play. Judging from the repulse response function and variance decomposition, the total employment figure will promote the increase of the GDP in the long run, and this promotion effect will last for a long time.

Meanwhile, the increase of the GDP will boost the rationalization and sophistication of the total employment figure. With the aim to promote a balanced development between the industrial structure and employment structure, the industrial structure of Hunan must be optimized and upgraded, and active employment policies should be implemented. So, we need to accelerate the development of modern agriculture and improve the comprehensive productivity of agriculture in Hunan; due attention should be paid to the coordinated development of labor-intensive industries and capital-and-technology-intensive industries and we can take advantages of human resources in Hunan; we need to speed up the development of the modern service industry and strive to construct an industry service system which is in accordance with the development of "Si Hua Liang Xing"; and we need to actively promote vocational training and improve the employment structure in Hunan.

\section{REFERENCES}

[1] G.Clark(1987), Conditions for economic development, Toyo Keizai: industrial economics.

[2] Simon Smith Kuznets (1985), The Commercial Press of Beijing: Economic growth in various countries.

[3] Sun Jian, Zhou Bing (2008.11), SEM analysis on the relevance of industrial structure and employment structure, Economic Review.

[4] Chen Dahong(2007.4), Analysis on the relevance of industrial structure and employment structure based on Beijing City, Northwest Population Journal.

[5] Liu Jinwei(2013.5), Analysis on the industrial structure and employment structure of China, Guizhou Social Sciences. 